\title{
Serum copper decrease and cerebellar atrophy in patients with nitrous oxide-induced subacute combined degeneration: two cases report
}

\author{
Jie Cao ${ }^{\dagger}$, Lusen Ran ${ }^{\dagger}$, Chenchen Liu and Zhijun Li ${ }^{*}$ (0)
}

\begin{abstract}
Background: Subacute combined degeneration $(S C D)$ is a neurological complication commonly associated with vitamin $\mathrm{B}_{12}$ deficiency. It can result from nitrous oxide $\left(\mathrm{N}_{2} \mathrm{O}\right)$ abuse and cause neuropsychiatric symptoms. However, there has been no literature regarding alterations of serum copper and cerebellum in SCD patients.

Case presentation: We reported two cases of young SCD patients with histories of $\mathrm{N}_{2} \mathrm{O}$ abuse. In these cases, elevated homocysteine, macrocytic anemia, spinal cord abnormalities, and peripheral nerve injuries were detected. In addition, decreased serum copper level and cerebellar atrophy were reported for the first time. The patients'symptoms improved after withdrawal of $\mathrm{N}_{2} \mathrm{O}$ exposure and vitamin $\mathrm{B}_{12}$ supplements.
\end{abstract}

Conclusion: We reported two SCD cases with serum copper alteration and cerebellar atrophy after $\mathrm{N}_{2} \mathrm{O}$ abuse for the first time. These might be crucial complements to the diagnosis of SCD.

Keywords: Nitrous oxide, Subacute combined degeneration, Serum copper, Cerebellar atrophy, Cognitive decline

\section{Background}

Subacute combined degeneration (SCD) is a neurological disease usually induced by vitamin $B_{12}$ deficiency [1-4]. Previous studies demonstrate that SCD can result from recreational nitrous oxide $\left(\mathrm{N}_{2} \mathrm{O}\right)$ abuse and cause various neuropsychiatric disorders [5-9]. However, no literature has been concerned about the serum copper and cerebellar changes through the diagnostic process. Here for the first time, we report two cases of SCD patients induced by $\mathrm{N}_{2} \mathrm{O}$ abuse with decreased cupric ion and cerebellar atrophy, intending to explore new clinical features of the disease.
*Correspondence: zjlhuazhong@163.com

${ }^{\dagger} \mathrm{Jie}$ Cao and Lusen Ran contributed equally to this work.

Department of Neurology, Tongji Hospital, Tongji Medical College,

Huazhong University of Science and Technology, Wuhan 430030, China

\section{Case presentation \\ Case 1}

A 20-year-old woman complained of weakness and numbness in both lower limbs for 10 days. She had inhaled $\mathrm{N}_{2} \mathrm{O}$ gas for over a year before admission. Physical examination showed decreased muscle strength in both lower limbs (grade 4/5) and deep sensational disturbances in extremities. The muscle tension was normal, and the tendon reflex of the limbs was symmetrically active. The patient also had a "drunken" gait, "explosive speech", nystagmus, and cerebellar ataxia (positive Romberg sign, abnormal finger-to-nose and heel-to-shin tests with eyes open or closed).

Laboratory examinations showed increased serum vitamin $\mathrm{B}_{12}(>1525 \mathrm{pg} / \mathrm{mL}$, normal range $180-914 \mathrm{pg} /$ $\mathrm{mL}$ ) and decreased folic acid $(3.54 \mathrm{ng} / \mathrm{mL}$, normal range $>4.00 \mathrm{ng} / \mathrm{mL}$ ) levels. The serum homocysteine 
(15.5 umol/L, normal range 6.0-14.0 umol/L) level was increased, and the methylene tetrahydrofolate reductase (MTHFR) genotype reveals normal metabolic capacity. The blood routine test presented macrocytic anemia. The detection of metal ions revealed declined serum copper level (10.5 umol/L, normal range 12.6$24.4 \mathrm{umol} / \mathrm{L}$ ), and serum zinc level was within the normal range. The routine, biochemical, immunological, and etiological examination in cerebral spinal fluid appeared normal. Other laboratory examinations were within the normal range. The motor and sensitive nerve conduction velocities and electromyography showed decreased motor and sensitive nerve conduction velocities in extremities and sensorimotor polyneuropathy. Spinal MRI revealed abnormal signals in posterior and lateral columns of the spinal cords, presented as inverted "V"- shaped lesions (Fig. 1a, b). Brain MRI displayed slight cerebellar atrophy (Fig. 2a, b). Besides, she had poor cognitive behavior with a mini-mental state examination (MMSE) score of 18.
The patient was diagnosed with SCD and asked to stop $\mathrm{N}_{2} \mathrm{O}$ inhalation. Ten days after cobalamin, folate, and symptomatic treatment, the homocysteine level returned to normal. Four days later, the patient was discharged with reduced limb numbness and slightly increased muscle strength of both lower limbs than before.

The patient was asked to continue taking cobalamin and folate after discharge. At 2-week's follow-up, her walking function and cognitive behavior improved (MMSE score $=22$ ). Three months after discharge, the patient got recovered in the muscle strength and gait, but still felt numbness in toes. The patient completely recovered in the follow-up at 6 and 12 months after discharge respectively. The levels of serum vitamin $B_{12}$, folate, copper, and hemoglobin were all in the normal range at 3,6 , and 12 months after discharge.

\section{Case 2}

A 19-year-old woman complained of speech disorders, weakness, and numbness of her lower limbs for 2 weeks.
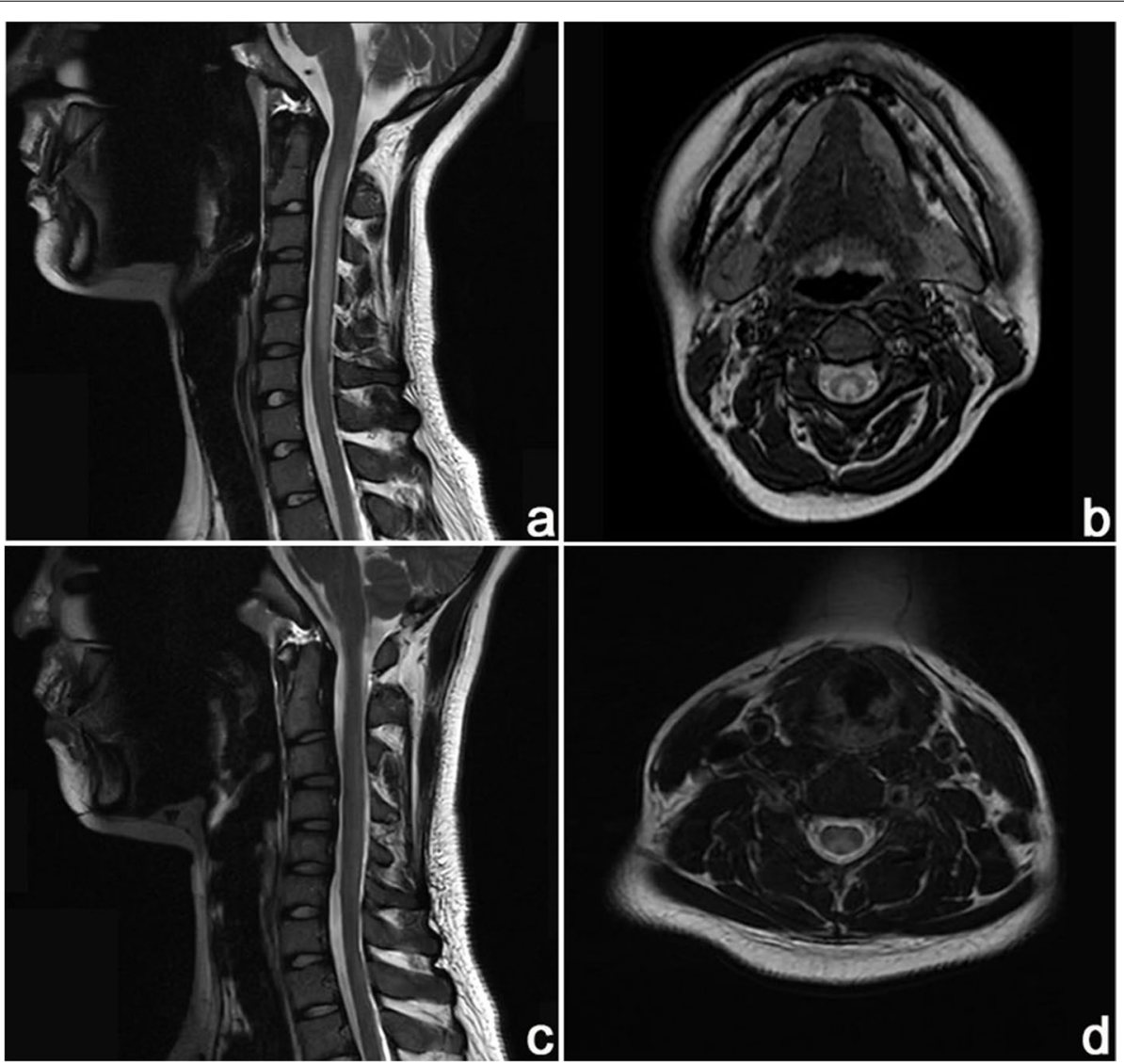

Fig. 1 Spinal MRI findings of the two patients. In case 1, (a) sagittal $T_{2}$-weighted imaging showed symmetrical hyperintensities from $C 2$ to $C 5$ segment in both posterior and lateral columns of the spinal cords, and (b) axial T2-weighted imaging revealed typical inverted " $V$ "- shaped lesion. In case 2, (c) sagittal $\mathrm{T}_{2}$-weighted imaging showed symmetrical hyperintensities from C2 to T1 segment in both posterior and lateral columns of the spinal cords, and (d) axial $\mathrm{T}_{2}$-weighted imaging revealed typical inverted " $\mathrm{V}$ "- shaped lesion 

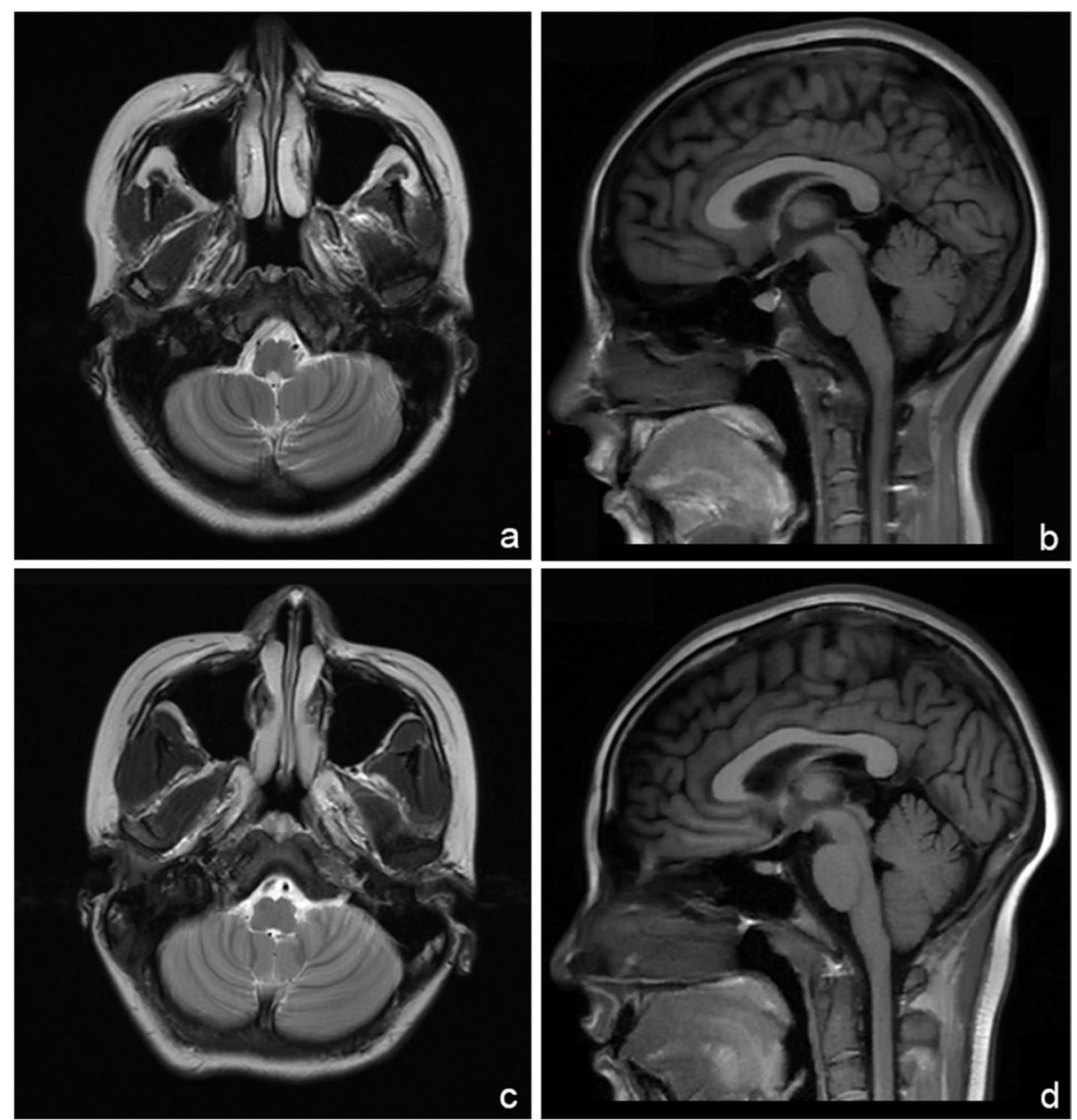

Fig. 2 Brain MRI findings of the two patients. Axial T2-weighted imaging and sagittal T1-weighted imaging showed enlarged cerebellar sulci in (a, b) case 1 and $(\mathbf{c}, \mathbf{d})$ case 2 relatively, indicating cerebellar atrophies

She had inhaled $\mathrm{N}_{2} \mathrm{O}$ gas for nearly one year and the dose was largely increased in the recent two months. Half a year after inhalation, she began to take vitamin B complex irregularly. The patient hummed and talked discontinuously, and also presented intermittent hallucinations during the conversation on admission. Physical examination showed decreased muscle strength of lower limbs (grade 4/5), declined muscle tension, hypoesthesia, and deep sensational disturbances in extremities. The patient also had a "drunken" gait, "explosive speech", nystagmus, and cerebellar ataxia (positive Romberg sign, abnormal finger-to-nose and heel-to-shin tests with eyes open or closed).

Laboratory examinations showed increased serum vita$\min \mathrm{B}_{12}(>1515 \mathrm{pg} / \mathrm{mL}$, normal range $180-914 \mathrm{pg} / \mathrm{mL})$ level and macrocytic anemia. The serum homocysteine (22.6 umol/L, normal range 6.0-14.0 umol/L) level was increased, and the methylene tetrahydrofolate reductase (MTHFR) genotype revealed normal metabolic capacity.
We were also concerned about the copper metabolism and found decreased serum copper $(10.1 \mathrm{umol} / \mathrm{L}$, reference range 12.6-24.4 umol/L) and ceruloplasmin $(0.194 \mathrm{~g} / \mathrm{L}$, reference range $0.22-0.58 \mathrm{~g} / \mathrm{L})$ levels. The serum zinc level was within the normal range. The routine, biochemical, immunological, and etiological examination in cerebral spinal fluid appeared normal. Other laboratory examinations were within the normal range. The motor and sensitive nerve conduction velocities and electromyography showed decreased motor and sensitive nerve conduction velocities in extremities and sensorimotor polyneuropathy. Spinal MRI revealed abnormal signals in posterior and lateral columns of the spinal cords, presented as inverted "V"- shaped lesions (Fig. 1c, d). Brain MRI indicated slight cerebellar atrophy (Fig. 2c, d). She had poor cognitive behavior with an MMSE score of 14 on admission.

The patient was diagnosed with SCD and asked to stop $\mathrm{N}_{2} \mathrm{O}$ inhalation. After cobalamin, folate, and symptomatic 
treatment for 9 days, the homocysteine level returned to normal. She was discharged 2 days later with better cognitive performances (MMSE score increased to 28) and sensational function.

The patient was asked to continue taking cobalamin and folate after discharge. At 2-week's follow-up, she had much fewer hallucinations with the MMSE score of 30, but still walked unsteadily. Three months after discharge, the patient got recovered in the muscle strength and superficial sensation, but still had slight ataxia. The patient completely recovered in the follow-up at 6 and 12 months after discharge respectively. The levels of serum vitamin $B_{12}$, folate, copper, and hemoglobin were all in the normal range at 3,6 , and 12 months after discharge.

\section{Discussion and conclusions}

In recent years, $\mathrm{N}_{2} \mathrm{O}$ has gained increasing popularity worldwide especially among young people due to its euphoric effects $[10,11]$. According to previous studies, it is not unusual that $\mathrm{N}_{2} \mathrm{O}$ can cause cobalamin deficiency and SCD $[5,7,11-13]$. Although serum vitamin $B_{12}$ is a most convenient and accessible laboratory approach to evaluate cobalamin deficiency, it is to note that quite a few SCD patients are detected with normal or elevated serum vitamin $B_{12}$ [14-17]. In fact, a growing number of $\mathrm{N}_{2} \mathrm{O}$ addicts are beginning to take vitamin $\mathrm{B}_{12}$ irregularly before admission. Even if patients do not take the supplements after inhaling $\mathrm{N}_{2} \mathrm{O}$, serum vitamin $\mathrm{B}_{12}$ levels may also be in the normal range [18]. A meta-analysis manifests that about a third of SCD patients are detected with no-low serum vitamin $B_{12}$ levels [19]. In a systematic review, Garakani et al. indicate that only less than half of adolescents with $\mathrm{N}_{2} \mathrm{O}$ abuse disclosed low levels of serum vitamin $\mathrm{B}_{12}$ [18].

These bring about challenges to traditional diagnostic thought that the total serum vitamin $B_{12}$ is the most preferential indicator to diagnose SCD. Literature suggests that a SCD patient with a normal or elevated level of serum vitamin $B_{12}$ may still have a vitamin $B_{12}$ shortage in the body, which is also described as functional vitamin $B_{12}$ deficiency [20]. It has been gradually realized that serum vitamin $B_{12}$ does not reflect genuine "active" vitamin $B_{12}$ level. Compared with serum vitamin $B_{12}$, there are more sensitive markers to reveal cobalamin deficiency at the tissue level, such as methylmalonic acid and homocysteine $[21,22]$. Therefore, it is reasonable to use combined serological indicators for assessing vita$\min B_{12}$ deficiency. As is shown in our cases, the declined level of serum vitamin $B_{12}$ is not a compulsory element for SCD diagnosis, while an elevated level of homocysteine is helpful for the evaluation of functional vitamin $B_{12}$ deficiency.
Copper is one of the trace elements which plays an important role as a component of enzymes in the nervous system [23]. As an essential element of methionine synthase in the methylation cycle, the lack of serum copper leads to dysfunction of methionine synthase, which can cause demyelination that resembles SCD [24, 25]. The pathological copper deficiency was usually caused by insufficient storage (preterm and infants), insufficient intakes or malabsorption (diet causes, chronic diarrhea, celiac disease, Crohn's disease, long-time parenteral nutrition, intestinal surgery, and excessive zinc), increased demands (pregnancy, lactation and wound healing), increased losses (major burns and renal replacement therapy), or hereditary diseases (such as Menkes disease) $[26,27]$. As our cases had clear histories of $\mathrm{N}_{2} \mathrm{O}$ abuse and none of the above causes were involved, we suspected a possible link between the copper deficiency and $\mathrm{N}_{2} \mathrm{O}$ abuse. So far as we know, this is the first report concerning the alteration of serum copper in SCD following $\mathrm{N}_{2} \mathrm{O}$ abuse. To our knowledge, there has been no statement why $\mathrm{N}_{2} \mathrm{O}$ abuse could cause copper deficiency in previous articles. We speculated the possible reasons are as follows: Copper is a cofactor for a variety of biological reactions and thought to be necessary for methionine synthase and S-adenosylhomocysteine hydrolase, which play vital roles within the methylation cycle [10]. $\mathrm{N}_{2} \mathrm{O}$ can oxidize the cobalt ion which attenuates the function of methylcobalamin, inhibits methionine synthase, and elevates the concentration of homocysteine [5]. This might be followed by a decrease in the activity of S-adenosylhomocysteine hydrolase and a consequent decline in copper concentration by feedback regulations. However, more studies are needed to uncover the possible mechanism.

SCD generally affects the spinal cord and peripheral nerves, but rarely impacts the brain $[28,29]$. The essential brain pathological manifestation involves demyelination in the cerebral white matter [30]. However, there has been no report of cerebellar atrophy following SCD up to the present. To exclude cerebral atrophy induced by other diseases, the histories of our patients were asked repeatedly. Any symptoms in the nervous system, like speech disorder, weakness, clumsiness, abnormal sensation, unsteady gait, dizziness, etc., did not exist before $\mathrm{N}_{2} \mathrm{O}$ abuse. Through asking detailed histories, present causes for cerebral atrophy, like multiple system atrophy, intracranial infection, paraneoplastic syndrome, hereditary diseases (such as spinocerebellar degeneration, Friedreich ataxia, and dentatorubral-pallidoluysian atrophy), alcohol/drug abuse, traumatic brain injury, cerebrovascular disorders, etc. [31-33], were also excluded. As both of the young patients were with no medical or family histories 
before $\mathrm{N}_{2} \mathrm{O}$ inhalation, it was unlikely that the atrophies of our cases were caused by other reasons. We thus suspect that these changes resulted from $\mathrm{N}_{2} \mathrm{O}$ abuse. Our article is the first report involving cerebellar atrophy following $\mathrm{N}_{2} \mathrm{O}$ abuse, which diversifies brain changes in SCD patients. Previous literature argues that the cerebellum has a smaller requirement for vitamin $B_{12}$, which may indicate smaller storage of vitamin $B_{12}$ in the cerebellum. Therefore, the cerebellum may be more sensitive to chronic vitamin $B_{12}$ deficiency. This is perhaps a potential cause of cerebellum ataxia under a long-course vitamin $B_{12}$ deficiency $[34,35]$. Although the mechanism is vague, it highlights the harmfulness of $\mathrm{N}_{2} \mathrm{O}$ abuse as a long-term recreational purpose from neuroimaging studies.

Our article provided potential importance to sophisticate the diagnosis of SCD. Here we reported two cases of young SCD patients after $\mathrm{N}_{2} \mathrm{O}$ abuse, who were both detected with elevated vitamin $B_{12}$, declined serum copper, and cerebellar atrophy. It is supposed that the serum copper and cerebellar alteration could be auxiliary diagnostic indicators of SCD. These may be meaningful for comprehensive diagnoses of SCD patients.

\section{Abbreviations}

SCD: Subacute combined degeneration; $\mathrm{N}_{2} \mathrm{O}$ : nitrous oxide; MTHFR: methylene tetrahydrofolate reductase; MMSE: Mini-mental State Examination.

\section{Acknowledgements}

Not applicable.

\section{Authors' contributions}

$J C$ and LR collected the case information and drafted the manuscript. CL revised the manuscript. ZL discovered the case and revised the manuscript for intellectual content. All authors have read and approved the final version of the manuscript.

\section{Funding}

No funding was obtained for this article.

\section{Availability of data and materials}

The data that support the findings of the current study are available form the corresponding author upon reasonable request.

\section{Declarations}

\section{Ethics approval and consent to participate}

Not applicable.

\section{Consent for publication}

Written informed consent was obtained from both patients and the patients legal guardians for publication of the cases and any accompanying data. This report does not contain any personal information that could lead to the identification of the patient.

\section{Competing interests}

The authors declare that they have no competing interests.

Received: 20 April 2021 Accepted: 17 November 2021

Published online: 04 December 2021

\section{References}

1. Lanska DJ. Chapter 30: historical aspects of the major neurological vitamin deficiency disorders: the water-soluble B vitamins. Handb Clin Neurol. 2010;95:445-76.

2. Lever EG, Elwes RD, Williams A, Reynolds EH. Subacute combined degeneration of the cord due to folate deficiency: response to methyl folate treatment. J Neurol Neurosurg Psychiatry. 1986:49(10):1203-7.

3. Briani C, Dalla Torre C, Citton V, Manara R, Pompanin S, Binotto G, et al. Cobalamin deficiency: clinical picture and radiological findings. Nutrients. 2013;5(11):4521-39

4. Morishita A, Tomita H, Takaishi Y, Nishihara M, Kohmura E. A case of subacute combined degeneration of the spinal cord diagnosed by characteristic findings of magnetic resonance imaging: case report and review of 22 cases. No Shinkei Geka. 2005;33(5):489-95.

5. Jiang J, Shang $X$. Clinical-radiological dissociation in a patient with nitrous oxide-induced subacute combined degeneration: a case report. BMC Neurol. 2020;20(1):99.

6. Samia AM, Nenow J, Price D. Subacute combined degeneration secondary to nitrous oxide abuse: quantification of use with patient follow-up. Cureus. 2020;12(10):e11041.

7. Zhao B, Zhao L, Li Z, Zhao R. Subacute combined degeneration induced by nitrous oxide inhalation: two case reports. Medicine (Baltimore). 2020;99(18):e19926.

8. Chen HJ, Huang CS. Nitrous oxide-induced subacute combined degeneration presenting with dystonia and Pseudoathetosis: a case report. Acta Neurol Taiwanica. 2016;25(2):50-5.

9. Choi C, Kim T, Park KD, Lim OK, Lee JK. Subacute combined degeneration caused by nitrous oxide intoxication: a report of two cases. Ann Rehabil Med. 2019;43(4):530-4.

10. Emmanouil DE, Quock RM. Advances in understanding the actions of nitrous oxide. Anesth Prog. 2007:54(1):9-18.

11. Lan SY, Kuo CY, Chou CC, Kong SS, Hung PC, Tsai HY, et al. Recreational nitrous oxide abuse related subacute combined degeneration of the spinal cord in adolescents - a case series and literature review. Brain and Development. 2019;41(5):428-35.

12. Yuan JL, Wang SK, Jiang T, Hu WL. Nitrous oxide induced subacute combined degeneration with longitudinally extensive myelopathy with inverted V-sign on spinal MRI: a case report and literature review. BMC Neurol. 2017;17(1):222.

13. Patel KK, Mejia Munne JC, Gunness VRN, Hersey D, Alshafai N, Sciubba $D$, et al. Subacute combined degeneration of the spinal cord following nitrous oxide anesthesia: a systematic review of cases. Clin Neurol Neurosurg. 2018;173:163-8.

14. Cao J, Su ZY, Xu SB, Liu CC. Subacute combined degeneration: a retrospective study of 68 cases with short-term follow-up. Eur Neurol. 2018;79(5-6):247-55.

15. Divate PG, Patanwala R. Neurological manifestations of $B(12)$ deficiency with emphasis on its aetiology. J Assoc Physicians India. 2014;62(5):400-5.

16. Hemmer B, Glocker FX, Schumacher M, Deuschl G, Lücking CH. Subacute combined degeneration: clinical, electrophysiological, and magnetic resonance imaging findings. J Neurol Neurosurg Psychiatry. 1998;65(6):822-7.

17. Li J, Ren M, Dong A, Wu Y, Han N, Deng B, et al. A retrospective study of 23 cases with subacute combined degeneration. Int J Neurosci. 2016;126(10):872-7.

18. Garakani A, Jaffe RJ, Savla D, Welch AK, Protin CA, Bryson EO, et al. Neurologic, psychiatric, and other medical manifestations of nitrous oxide abuse: a systematic review of the case literature. Am J Addict. 2016;25(5):358-69.

19. Cao J, Xu S, Liu C. Is serum vitamin B12 decrease a necessity for the diagnosis of subacute combined degeneration?: a meta-analysis. Medicine (Baltimore). 2020;99(14):e19700.

20. Sobczyńska-Malefora A, Gorska R, Pelisser M, Ruwona P, Witchlow B, Harrington DJ. An audit of holotranscobalamin ("active" B12) and methylmalonic acid assays for the assessment of vitamin B12 status: application in a mixed patient population. Clin Biochem. 2014;47(1-2):82-6.

21. Green R. Indicators for assessing folate and vitamin B-12 status and for monitoring the efficacy of intervention strategies. Am J Clin Nutr. 2011;94(2):666s-72s. 
22. Ulrich A, Müller $D$, Linnebank M, Tarnutzer AA. Pitfalls in the diagnostic evaluation of subacute combined degeneration. BMJ Case Rep. 2015;2015:bcr2014208622.

23. van Dijkman SC, de Jager NCB, Rauwé WM, Danhof M, Della PO. Effect of age-related factors on the pharmacokinetics of Lamotrigine and potential implications for maintenance dose optimisation in future clinical trials. Clin Pharmacokinet. 2018;57(8):1039-53.

24. Winston GP, Jaiser SR. Copper deficiency myelopathy and subacute combined degeneration of the cord - why is the phenotype so similar? Med Hypotheses. 2008;71(2):229-36.

25. Nakamura T, Nishi M, Rikitake M, Koga D, Eto J, Tajima D, et al. A case of subacute combined degeneration of the spinal cord due to folic acid and copper deficiency. Brain and Development. 2019;41(1):111-5.

26. Altarelli M, Ben-Hamouda N, Schneider A, Berger MM. Copper deficiency: causes, manifestations, and treatment. Nutr Clin Pract. 2019;34(4):504-13.

27. King D, Siau K, Senthil L, Kane KF, Cooper SC. Copper deficiency myelopathy after upper gastrointestinal surgery. Nutr Clin Pract. 2018;33(4):515-9.

28. Chen H, Li H, Li Y, Jing J, Raza HK, Zhang Z, et al. Clinical and imaging characteristics of subacute combined degeneration complicated with white matter lesions in the brain: a report of five cases. Somatosens Mot Res. 2018;35(2):119-23.

29. Minn YK, Kim SM, Kim SH, Kwon KH, Sunwoo IN. Sequential involvement of the nervous system in subacute combined degeneration. Yonsei Med J. 2012;53(2):276-8.

30. Surtees R. Biochemical pathogenesis of subacute combined degeneration of the spinal cord and brain. J Inherit Metab Dis. 1993;16(4):762-70.

31. Gellersen HM, Guo CC, O'Callaghan C, Tan RH, Sami S, Hornberger M. Cerebellar atrophy in neurodegeneration-a meta-analysis. J Neurol Neurosurg Psychiatry. 2017;88(9):780-8.

32. Karakaya M, Paketci C, Altmueller J, Thiele H, Hoelker I, Yis U, et al. Biallelic variant in AGTPBP1 causes infantile lower motor neuron degeneration and cerebellar atrophy. Am J Med Genet A. 2019;179(8):1580-4.

33. Mavroudis I. Cerebellar pathology in Alzheimer's disease. Hell J Nucl Med. 2019;22(Suppl):174-9.

34. Morita S, Miwa H, Kihira T, Kondo T. Cerebellar ataxia and leukoencephalopathy associated with cobalamin deficiency. J Neurol Sci. 2003;216(1):183-4.

35. Chakrabarty B, Dubey R, Gulati S, Yoganathan S, Kumar A, Kumar A. Isolated cerebellar involvement in vitamin B12 deficiency: a case report. J Child Neurol. 2014;29(11):Np161-3.

\section{Publisher's Note}

Springer Nature remains neutral with regard to jurisdictional claims in published maps and institutional affiliations.

Ready to submit your research? Choose BMC and benefit from:

- fast, convenient online submission

- thorough peer review by experienced researchers in your field

- rapid publication on acceptance

- support for research data, including large and complex data types

- gold Open Access which fosters wider collaboration and increased citations

- maximum visibility for your research: over 100M website views per year

At BMC, research is always in progress.

Learn more biomedcentral.com/submissions 